\title{
Interventricular septal expansion of a sinus of Valsalva aneurysm: a rare cause of complete heart block
}

\author{
M I Walters, D Ettles, L Guvendik, G C Kaye
}

\begin{abstract}
Department of
Cardiology, East

Yorkshire

Cardiothoracic

Centre, Cottingham,

East Yorkshire HU16

5JQ, UK

M I Walters

D Ettles

L Guvendik

Dr GC Kaye

Correspondence to: Dr Walters.

Accepted for publication 14 January 1998 (Pacesetter, Coventry, UK) dual chamber pacemaker was subsequently implanted with complete resolution of cardiac symptoms.

He remained well for three months when he presented with sudden onset dyspnoea in January 1996. Further examination at this time revealed signs of pulmonary congestion and a cardiac murmur throughout systole and diastole that had changed in character from the previous evaluation. There were no peripheral signs of infective endocarditis. Initial management with intravenous diuretics resulted in rapid clinical improvement and allowed the following sequence of investigations:
\end{abstract}

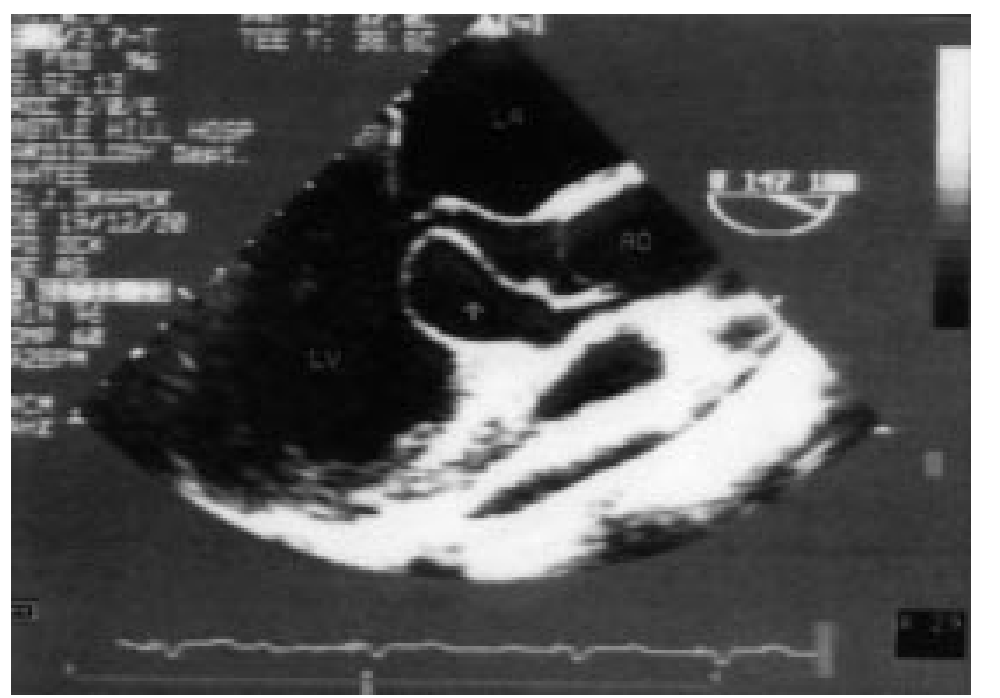

Figure 1 Transoesophageal echocardiogram showing the marked expansion of a sinus of Valsalva aneurysm (arrow) into the interventricular septum. LV, left ventricle; Ao, aorta; $L A$, left atrium.

We present the case of a 64 year old man, previously of good health, who presented in November 1995 with a short history of presyncope and one witnessed episode of syncope. On admission he was clinically in complete heart block with a ventricular rate of 40 beats $/ \mathrm{min}$ but had a well maintained blood pressure at $150 / 80 \mathrm{~mm} \mathrm{Hg}$. Auscultation revealed a soft systolic murmur in the aortic area. The remainder of the examination was unremarkable. Resting ECG confirmed complete AV block with a slow regular broad complex ventricular escape rhythm. A Paragon III 
heard at the base of the heart. As the aneurysm often ruptures into the right heart structures (right atrium or ventricle), right sided cardiac failure often follows quickly. The pattern of presentation does however vary widely, and unruptured aneurysms are often "silent" or present only with vague non-specific symptoms. However, cerebrovascular embolisation ${ }^{4}$ and angina ${ }^{5}$ have been reported. In our patient the unruptured aneurysm had extended into the interventricular septum and, presumably through compression, had compromised normal AV nodal/His bundle function and resulted in complete heart block. Case reports of the latter association are very rare, and to our knowledge only one case of an antemortem diagnosis has been reported previously. ${ }^{6}$ Therefore, sinus of
Valsalva aneurysm deserves to be considered as a rare cause of complete heart block.

1 Matsumoto Y, Kubo T, Tagawa H, et al. An autopsy case of the sinus of Valsalva aneurysm involved with tuberculous inflammation, leading to complete heart block. Kokyu to inflammation, leading to

2 Koh KK, Lee KH, Kim SS, et al. Ruptured aneurysm of the sinus of valsalva in a patient with Behçet's disease. Int $\mathcal{F}$ Cardiol 1994;47:177-9.

3 van Son JA, Danielson GK, Schaff HV, et al. Long term outcome of surgical repair of ruptured sinus of valsalva aneurysm. Circulation 1994;90(5 pt 2):II20-9.

4 Shahrabani RM, Jairaj PS. Unruptured aneurysms of the sinus of valsalva: a potential source of cerebrovascular sinus of valsalva: a potential source

5 Tami LF, Turi ZG, Arbulu A. Sinus of Valsalva aneurysms involving both coronary ostia. Catheter Cardiovasc Diagn 1993;29:304-8

6 Abad C. Congenital aneurysm of the sinus of valsalva dissecting into the interventricular septum. Cardiovasc Surg 1995;3:563-4

\section{SHORT CASES IN CARDIOLOGY}

Department of

Cardiology,

Isesaki-Sawa Medical

Association Hospital,

T372-0024

Shimouekimachi 481 ,

Isesaki, Japan

J Hoshino

F Naganuma

Second Department of

Internal Medicine,

Gunnma University

School of Medicine,

Maebashi, Japan

R Nagai

Correspondence to:

Dr Hoshino.

Accepted for publication 29 January 1998
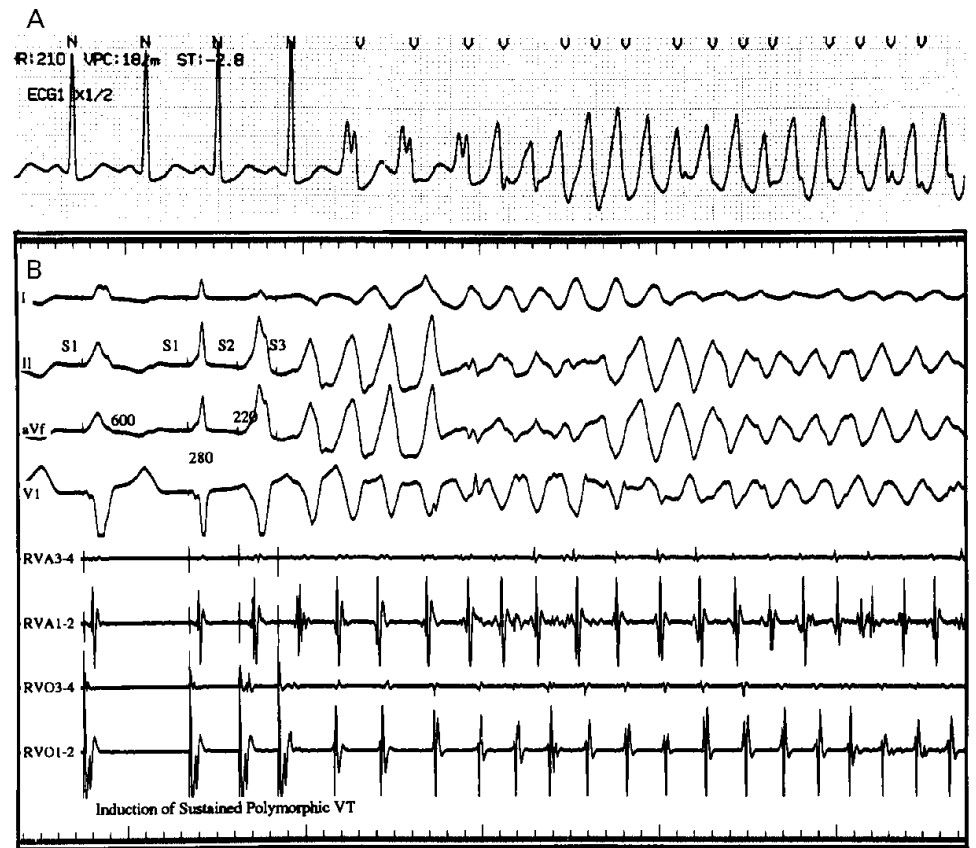

Figure 1 (A) After an extrasystole, electrocardiography shows ventricular fibrillation. (B) Sustained polymorphic ventricular tachycardia was readily induced by double extrastimuli delivered from the right ventricle outflow tract in the control state.

\author{
J Hoshino, F Naganuma, R Nagai
}

A 40 year old Japanese man fainted suddenly while fishing and was brought to hospital. He fainted again in the outpatient department. Electrocardiography showed ventricular fibrillation (fig 1A), and sinus rhythm was recovered by defibrillation with $200 \mathrm{~J}$. He had no history of syncope or life threatening arrhythmias. A

\section{Ventricular fibrillation triggered by a ruptured sinus of Valsalva aneurysm}

grade V/VI continuous murmur was accompanied by a diastolic thrill along the left sternal border. Electrocardiography showed negative $\mathrm{T}$ waves in leads II, III, aVF, and V4-6. Transoesophageal echocardiography with colour Doppler imaging showed an aneurysm of the right coronary sinus of Valsalva, which displaced towards the right ventricle, and had systolic-diastolic turbulent flow from the aorta into the right ventricle (fig 2).

Catheterisation of the right heart revealed moderate increases of the pulmonary arterial and right ventricular systolic pressures. Blood oxygen saturation was increased by $12 \%$, from $79.9 \%$ at the right atrium to $91.8 \%$ at the right ventricle. The left to right shunting rate was $42 \%$ and the pulmonary to systemic flow ratio was 1.7 . Aortography revealed a jet of contrast medium flowing out of the right coronary sinus into the right ventricle.

The patient had surgery on the seventh hospital day. Intraoperatively, a strong thrill caused by the ruptured sinus of Valsalva aneurysm was palpated directly under the pulmonary arterial valve. The aneurysm was Konno I type with a diameter of $6-7 \mathrm{~mm}$. A ventricular septal defect type I, 6-7 $\mathrm{mm}$ in diameter, was also found at the site. Postoperative electrophysiological examination showed that ventricular fibrillation was induced by continuous stimulation of the outflow route of the right ventricle (fig 1B). The postoperative course was favourable. Amiodarone $200 \mathrm{mg}$ daily was initiated to prevent ventricular fibrillation.

Rupture of an aneurysm of the sinus of Valsalva is rare, accounting for only $0.26 \%$ of all 


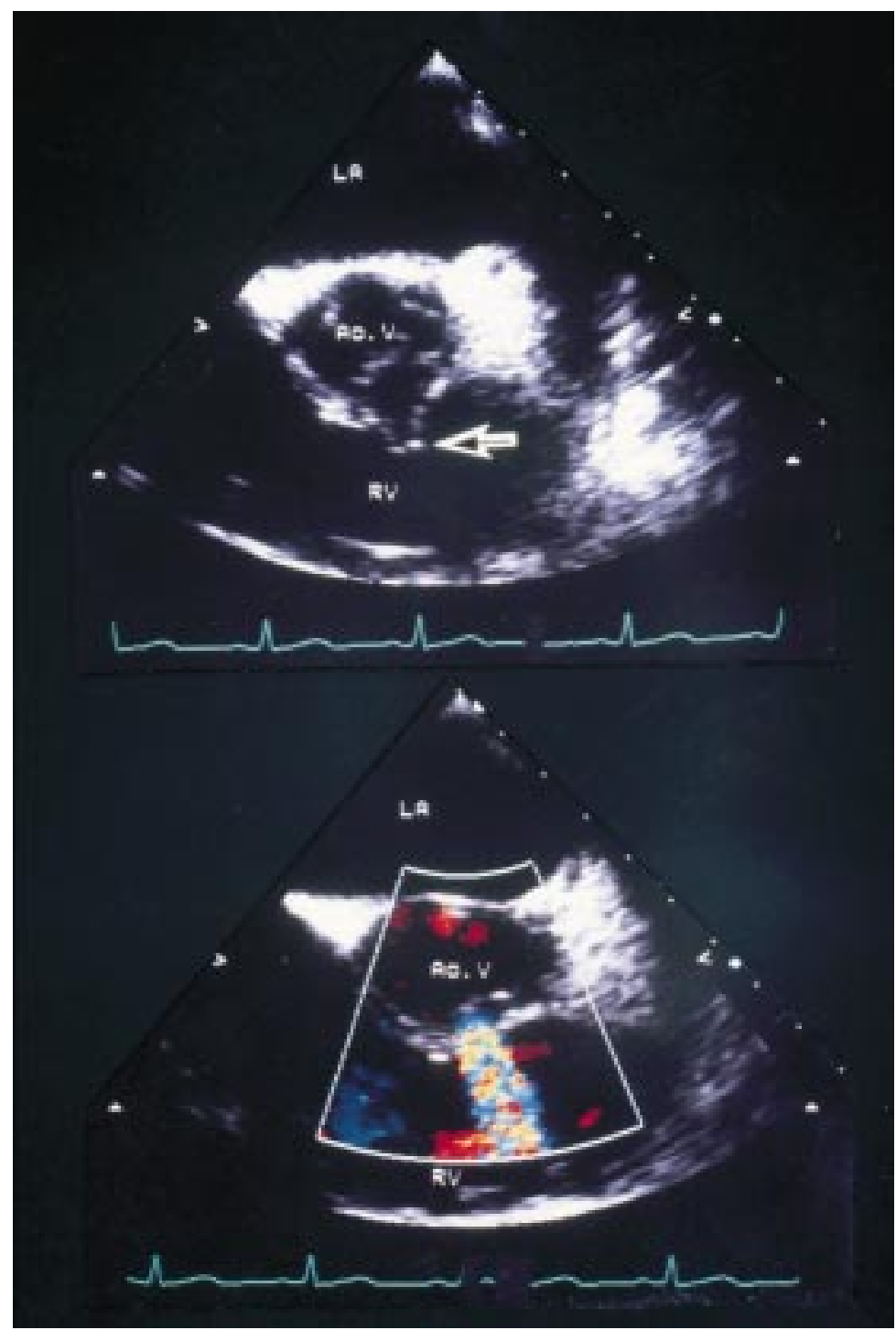

Figure 2 Transoesophageal echocardiography with colour flow Doppler showing systolic-diastolic turbulent flow from the aorta into the right ventricle.

surgical cases of congenital cardiac disease. ${ }^{1}$ Sinus of Valsalva aneurysm may result from a weak sinus of Valsalva wall. Recent studies have emphasised the wide variety of clinical manifestations of this lesion depending on its location and course. ${ }^{2}{ }^{3}$ Because complications such as ventricular septal defect are relatively frequent, the aetiology is assumed to be congenital weakness of the sinus of Valsalva, except in cases resulting from inflammation, infection, or necrosis. The aetiology of the our case was assumed to be congenital because the patient was only 40 years old and had a ventricular septal defect; there were no inflammatory findings.

There have been two reported cases of ventricular fibrillation caused by rare mechanical complications in sinus of Valsalva aneurysms. ${ }^{45}$ In one report, ${ }^{4}$ the mechanism of ventricular fibrillation was myocardial ischaemia caused by compression of the left circumflex artery induced by a large aneurysm of the left sinus of Valsalva. In the other report, ${ }^{5}$ a ruptured aneurysm of the sinus of Valsalva had dissected into the ventricular septum and was complicated by ventricular fibrillation. No such complications were found in our patient. The origin of the aneurysm, the chamber into which it ruptured, and the association with a ventricular septal defect were typical for aneurysm of the sinus of Valsalva. However, the left to right shunting rate $(42 \%)$ was enough to cause a rapid change in circulatory dynamics. Although ventricular fibrillation was easily induced by extrastimulation, our patient had no history of syncope or life threatening arrhythmias. These findings suggest that, in the absence of a rare mechanical complication, a ruptured aneurysm of the sinus of Valsalva may precipitate ventricular fibrillation because of an abrupt change in circulatory dynamics, if the patient has a tendency towards ventricular fibrillation. No other similar cases have been reported.

We thank the following physicians for their help in the management of this patient; Tatsuo Kaneko, Akihiko Nogami, Hiroshi Kamiyama, Shigeru Oshima, and Tadashi Suzuki.

1 Jacques AM. Long term outcome of surgical repair of ruptured sinus of Valsalva aneurysm. Circulation 1994;90:1120-9.

2 Sakakibara S, Konno S. Congenital aneurysm of sinus of Valsalva. Anatomy and classification. Am Heart f 1962;63: 405-24.

3 Boutefeu JM, Moret PR, Hahn C, et al. Aneurysms of the sinus of Valsalva. Report of seven cases and review of the literature. Am f Med 1978;65:18-24.

4 Glock Y, Ferrarini JM, Puel J, et al. Isolated aneurysm of the left sinus of Valsalva. Rupture into the left atrium, left ventricle and dynamic coronary constriction. F Cardiovasc Surg Torino 1990;31:235-8

5 Engel PJ, Held JS, Bel KJ, et al. Echocardiographic diagnosis of congenital sinus of Valsalva aneurysm with dissection of the interventricular septum. Circulation 1981;63:705-11. 


\title{
Acquired coarctation of the aorta in William's syndrome
}

\author{
R Dhillon, T D Reddy, A Redington
}

The arterial lesions of William's syndrome are characteristic $^{1}$ : supravalvar aortic stenosis, coarctation of the aorta, peripheral pulmonary artery stenosis, and stenosis of the renal and coronary arteries. The development of slowly progressive coarctation has been described in only one patient, ${ }^{23}$ in whom angiography at 3 years of age showed a diffusely hypoplastic ascending aorta but no coarctation. Seven years later, angiography showed long segment coarctation distal to the left subclavian artery. We describe a patient in whom coarctation of the aorta developed over a much shorter time period.

\section{Case report}

William's syndrome was diagnosed in this boy at the age of 4 years on the basis of "elfin facies" comprising epicanthic folds, a shallow nasal bridge, anteverted nares, long philtrum, and prominent lips. ${ }^{4}$ Hypercalcaemia had been noted during infancy. At routine follow up aged 5 years his femoral pulses were weak, with normal upper limb pulses. Echocardiography showed supravalvar aortic stenosis but no discrete coarctation; however, in view of the compelling clinical signs, cardiac catheterisation was performed in April 1993. There was no demonstrable gradient between the ascending and descending aorta. Aortic angiography showed no coarctation, although the descending aorta was diffusely hypoplastic (fig 1). The narrowest luminal point distal to the left subclavian artery measured $6.1 \mathrm{~mm}$ compared to the widest diameter of $8.3 \mathrm{~mm}$.

In December 1996, clinical review again revealed weak femoral pulses with upper limb hypertension (right arm blood pressure 160/ $104 \mathrm{~mm} \mathrm{Hg}$ ). Echocardiography showed mild supravalvar aortic stenosis with a peak Doppler velocity of $2.0 \mathrm{~m} / \mathrm{s}$, moderate left ventricular hypertrophy, and suggested severe coarctation of the aorta distal to the left subclavian artery. Cardiac catheterisation was repeated in February 1997 when the patient was 9 years old. On this occasion, his systolic pressure gradient on withdrawal from the ascending to descending aorta was $44 \mathrm{~mm} \mathrm{Hg}$. Aortic angiography showed a long segment severe coarctation distal to the left subclavian artery (fig 1). Measurements performed at corresponding sites to the previous aortic angiography showed progressive coarctation, with a narrowest diameter of $2.6 \mathrm{~mm}$, although there had been continued growth of the descending aorta distally measuring $10.9 \mathrm{~mm}$. Five months later, he underwent end to end repair of coarctation with an interposition graft. Postoperative recovery was uncomplicated.

\section{Discussion}

The speed of development of aortic coarctation in this child is remarkable (less than four years). This does not represent a failure of growth. There was progressive narrowing of the lumen of the aorta, with the narrowest diameter falling from 6.1 to $2.6 \mathrm{~mm}$, although
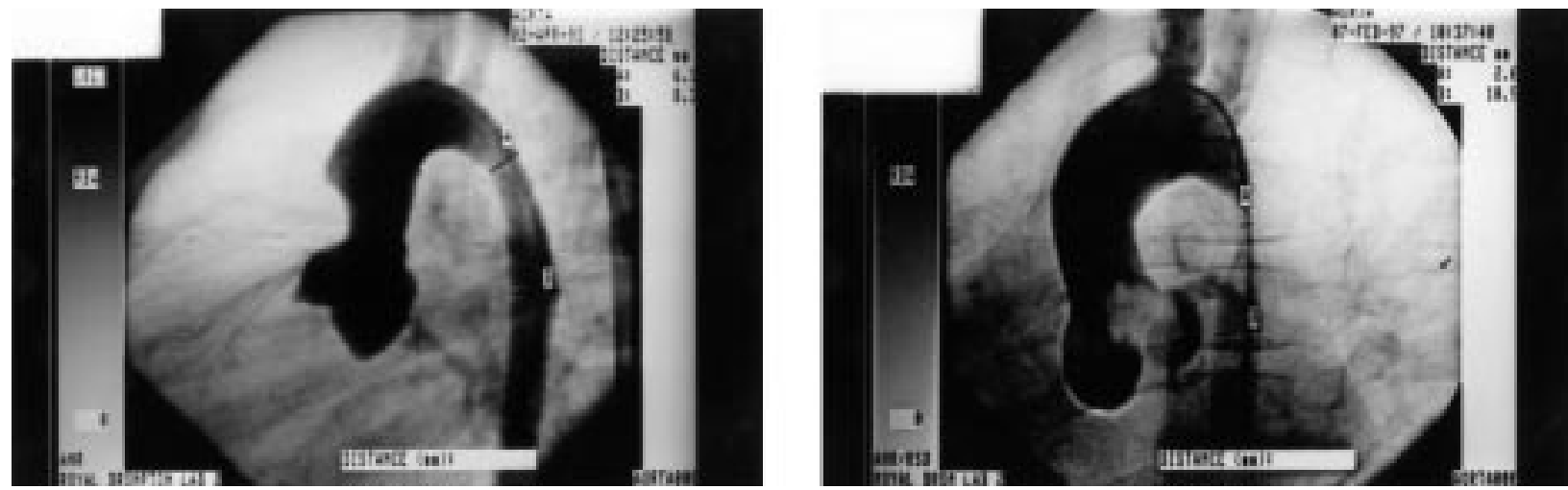

Figure 1 (Left) Aortic angiography performed in April 1993 showing narrowest site of thoracic descending aorta $6.1 \mathrm{~mm}(A)$ and widest site $8.3 \mathrm{~mm}$ (B). Supravalvar aortic stenosis is prominent. (Right) Aortic angiography performed in February 1997 in the same patient. Severe coarctation of the aorta distal to the left subclavian artery has developed, with a narrowest diameter of $2.6 \mathrm{~mm}(A)$. The aorta has continued to grow, with a widest thoracic descending aortic diameter of $10.9 \mathrm{~mm}(B)$. 
the widest lumen diameter distal to the site of coarctation increased over the same time interval, from 8.3 to $10.9 \mathrm{~mm}$. Furthermore, the histopathological examination of the resected segment of aorta revealed an external diameter of $7.0 \mathrm{~mm}$ compared with an internal diameter of $2.6 \mathrm{~mm}$. This severe luminal stenosis was largely the result of intimal proliferation, without obvious major medial hypertrophy, which is often described as an additional component of arterial wall thickening in this condition. ${ }^{5}$

Although the peripheral pulmonary artery stenoses of William's syndrome tend to improve, other vascular lesions become worse. ${ }^{1}$ Acquired coarctation of the aorta, however, is rare. $^{23}$ This case illustrates that the finding of weak femoral pulses in this situation may not be a reliable guide to the progression of coarctation, because of distal aortic hypoplasia. A high level of suspicion and regular echocardiographic follow up are necessary for the diagnosis of this unusual problem.

1 Zalzstein E, Moes CA, Musewe NN, et al. Spectrum of cardiovascular anomalies in Williams-Beuren syndrome. Pediatr Cardiol 1991;12:219-23.

2 Ino $\mathrm{T}$, Nishimoto $\mathrm{K}$, Iwahara $\mathrm{M}$, et al. Progressive vascular lesions in Williams-Beuren syndrome. Pediatr Cardiol 1988; 9:55-8.

3 Ino $\mathrm{T}$, Nishimoto $\mathrm{K}$, Iwahara $\mathrm{M}$, et al. Progressive vascular lesions in Williams syndrome. F Pediatr 1985;107:826.

4 Williams JCP, Barratt-Boyes BG, Lowe JB. Supravalvar aortic stenosis. Circulation 1961;24:1311-18.

5 Rein AJ, Preminger TJ, Perry SB, et al. Generalized arteriopathy in Williams syndrome: an intravascular ultrasound study. F Am Coll Cardiol 1993;21:1727-30.

\title{
SHORT CASES IN CARDIOLOGY
}

\section{Transcatheter recanalisation and stenting of a closed ductus arteriosus in duct dependent lung perfusion}

\author{
C Kampmann, C-F Wippermann, F-X Schmid
}

In patients with the congenital cardiac malformation of tetralogy of Fallot, occasionally one pulmonary artery, usually the left, seems angiographically to be absent. ${ }^{1}$ This pulmonary artery is usually present, but discontinuous with the pulmonary trunk, having originally been supplied by a patent arterial duct. With closure of the duct, the receiving flow to that pulmonary artery is by small collateral vessels, which leads to reduced growth of the involved pulmonary vessels and impedes definite surgical repair.

We report a case of a 2 day old, $1890 \mathrm{~g}$, premature, cyanotic boy (oxygen saturation $82 \%$ ) with tetralogy of Fallot, right sided aortic arch, and discontinuity between the pulmonary trunk and the left pulmonary artery with a distance of $6 \mathrm{~mm}$, and a complete left sided pulmonary perfusion deficiency. Six hours after starting prostaglandin $\mathrm{E}_{1}\left(\mathrm{PGE}_{1}\right)$ infusion $(100 \mathrm{ng} / \mathrm{kg} / \mathrm{min})$ there was still no flow to the left pulmonary artery or any increase in saturation.

Antegrade angiography from the right femoral vein confirmed the diagnosis. A closed patent arterial duct, originating from the left subclavian artery, could be seen selectively after passing the right ventricle into the overriding aorta (fig 1). To recanalise the closed patent arterial duct, an additional $50 \mathrm{ng} / \mathrm{kg} / \mathrm{min} \mathrm{PGE}_{1}$ was given over 10 minutes into the origin of the patent arterial duct, while it was attempted to pass a 0.014 inch floppy guidewire through the patent arterial duct.
After successfully passing the wire, $\mathrm{PGE}_{1}$ infusion was stopped and dilatation was performed up to $3 \mathrm{~mm}$. The length of ductal obliteration was $11 \mathrm{~mm}$. To maintain ductal patency, a $9 \mathrm{~mm}$ long coronary NIR stent was mounted on a $3.5 \mathrm{~mm}$ balloon catheter and implanted at the pulmonary end of the duct (fig 2). Postinterventional angiography showed a well developed left sided pulmonary arterial system, but without a main left pulmonary artery (fig 3).

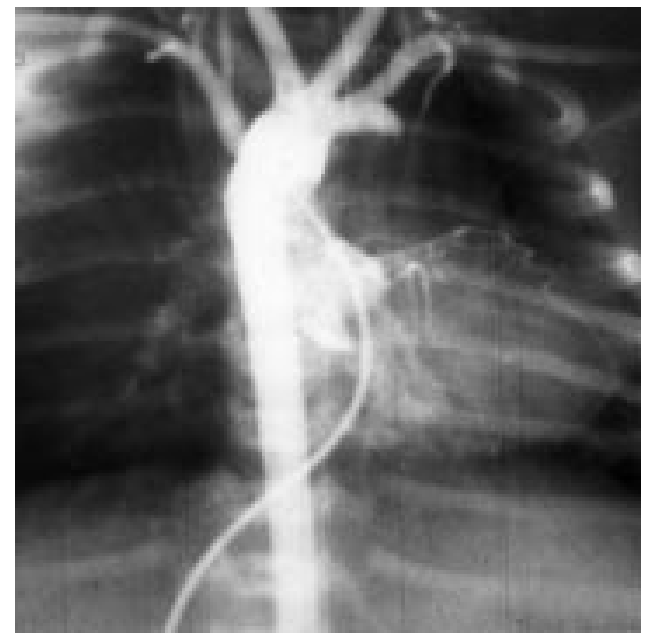

Figure 1 Selective posterior-anterior angiogram of the origin of the closed arterial duct from the left subclavian artery. 


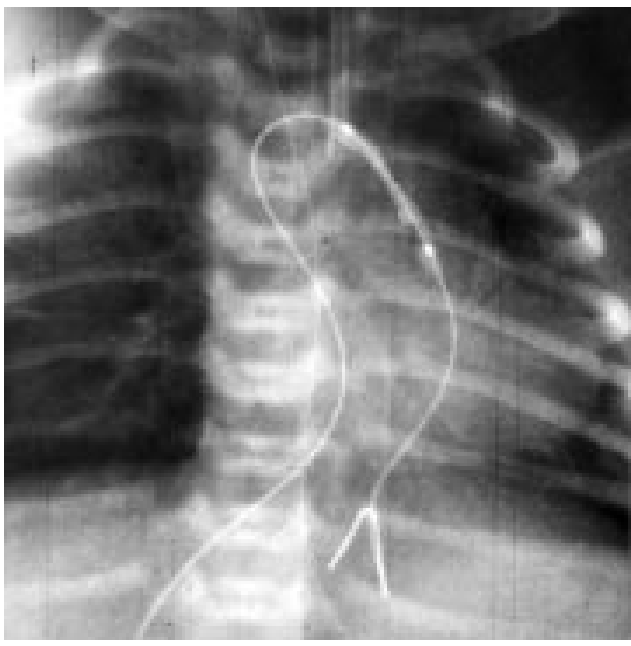

Figure 2 Angiogram of the arterial duct during stent implantation at the pulmonary end of the patent arterial duct.

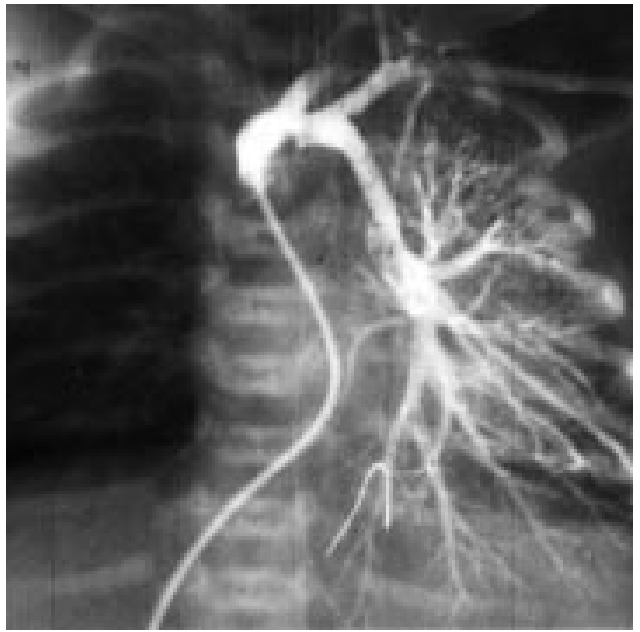

Figure 3 Selective angiogram of the left pulmonary artery after ductal stenting.

Immediately after stenting, the child developed left sided lung oedema with pleural effusion that necessitated drainage. After stenting, dilatation of the right ventricular outflow tract was performed up to $7 \mathrm{~mm}$. All interventions were without complication. Total fluoroscopy time was 18.6 minutes. Before stenting, antithrombin III was substituted to a blood level of $100 \%$ and a bolus of $100 \mathrm{U} / \mathrm{kg}$ heparin was given intravenously followed by continuous infusion of $400 \mathrm{U} / \mathrm{kg} /$ day for the next three days. The child was extubated on the next day and discharged 14 days later in very good condition (oxygen saturation 91\%); he was treated with $2 \mathrm{mg} / \mathrm{kg} /$ day propranolol and dipyridamole.

Redilatation of the stent up to $4.2 \mathrm{~mm}$ was necessary after 235 days. Selective angiograms of the right and left pulmonary arteries showed adequate development with diameters of 8 and $7.6 \mathrm{~mm}$, respectively, and mean right and left pressures of 10 and $13 \mathrm{~mm} \mathrm{Hg}$. At the age of 1 year the child had successful transatrialtranspulmonary repair of the tetralogy of Fallot with connection of the left pulmonary artery to the pulmonary trunk.

\section{Discussion}

In symptomatic newborns with tetralogy of Fallot, percutaneous balloon dilatation of the right ventricular outflow tract and the application of propranolol is used palliatively to provide ideal conditions for repair, ${ }^{2}$ although the dysplastic pulmonary valve may be damaged. ${ }^{3}$ Stenting of the patent arterial duct to maintain patency was first reported by Gibbs et al in patients with pulmonary atresia ${ }^{4}$ but required redilatation. ${ }^{5}$ In our case with duct dependent lung perfusion, adequate left pulmonary artery growth could be established by stenting the patent arterial duct. Interventional recanalisation combined with stenting of a closed patent arterial duct in man has not been reported previously. Early interventional recanalisation of closed patent arterial ducts is feasible even in premature neonates, and the procedure supports age appropriate development of pulmonary arteries. This should contribute to a reduction in perioperative mortality.

1 Jedeikin R, Rheuban KS, Carpenter MA, et al. Ductal origin of the left pulmonary artery in severe tetralogy of Fallot: of the left pulmonary artery in severe tetralogy of Fallot.

2 Sreeram N, Saleem M, Jackson M, et al. Results of balloon pulmonary valvuloplasty as a palliative procedure in tetralogy of Fallot. F Am Coll Cardiol 1991;18:59-65.

3 Battistessa SA, Robles A, Jackson M, et al. Operative findings after percutaneous balloon dilatation of the right ventricular outflow tract in tetralogy of Fallot. Br Heart $\mathcal{F}$ 1990;64:321-4.

4 Gibbs JL, Rothman MT, Rees MR, et al. Stenting of the arterial duct: a new approach to palliation for pulmonary atresia. Br Heart f 1992;67:240-5.

5 Rosenthal E, Quereshi SA, Tabtabaie AH, et al. Mediumterm results of experimental stent implantation into the ductus arteriosus. Am Heart $\mathcal{F}$ 1996;132:657-63. 